FUNDS to support research are becoming scarcer, so it is increasingly important to ensure that the money available is used as profitably as possible. For some years I have been suggesting that we are getting poorer and poorer value for the public money voted for research, and that an increasing fraction is being wasted on unnecessary and complicated administration. One of the fears aroused by the Rothschild recommendations was that they would make for additional complications and further waste. Even the most enthusiastic supporters of these changes cannot deny that there are many more scientists, individuals who were previously themselves engaged in research at the bench, who are now desk-bound planners, and that research funds are also spent on many more non-scientific administrators supporting (or even controlling) the scientific administrators. The hope is that this will result in the remaining bench workers devoting their time more profitably to more important projects.

In the meantime, it may be useful to try to find what sort of organisation is producing the most for the least expenditure. In the past, I have been accused of sentimentality for looking back nostalgically at the small units which operated efficiently in the 1930s, when funds were even tighter than today. I have been told that it is impossible to "put the clock back". The assumption is that the age of string, sealing wax and enthusiasm has gone for ever.

I have therefore been looking with interest at the performance of the Oil Pollution Research Unit of the Field Studies Council. Here we have a small group of young scientists working in converted cellars and outbuildings on a smaller total budget than that enjoyed by many individual academics who have received research council grants for studies which have made little noticeable impact on science or human welfare. At an international conference held at Aviemore in Scotland in April of this year, and sponsored by the Institute of Petroleum and the Field Studies Council, members of the unit described their work. It was clear that
this was both important and entirely relevant to the needs of the petroleum industry and to understanding the likely ecological effects of the exploitation of oil reserves. The work fulfilled all the

\section{Lab charges}

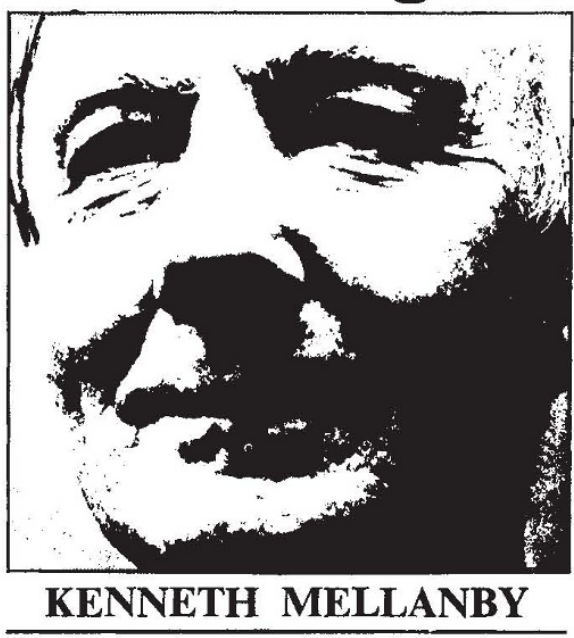

accepting contracts and making a much smaller surcharge. This is, in some circles, considered to be unfair competition. It is sugested that they should be compelled to charge more, for they are accused of not costing their work properly. As one with some experience of university administration, I do not think that this is the case, though the argument might appeal to empire-building registrars wishing to increase their own staff numbers. If $I$, as head of a department, had accepted a research contract, and it had included all the costs of staff and their equipment and materials, I would not have spent a penny more on running the department, nor would there have been any need for the central university administration to increase its costs. I might have had to write an occasional letter, but I would have hoped to compensate for this, and more, by

requirements that the Rothschild proposals are intended to produce.

The Oil Pollution Research Unit persuading the research workers to give (OPRU) has, however, shown that a a few of my lectures on subjects in very high proportion-more than $90 \%$ which they possessed a particular I would estimate-of their funds are expertise. I would have looked upon actually spent directly on research, pay- my relationship with the contract team ing salaries, equipping laboratories, as one of symbiosis, and not treated hiring facilities and visiting sites. The them as parasites.

parent body, the Field Studies Council, is itself an admirable organisation, with the least top-heavy administration of any comparable body. They do not have time to interfere in the running of the OPRU, though they are available to give help where this is required. The main lesson to be learned from this research organisation is, once more, that "small is beautiful", or at least that the small unit can still be the least wasteful.

I think that many other organisations could learn from this example. Their overheads are very much higher, though their productivity is, on the whole, lower. We hear many complaints from government departments, who have funds to commission research, that some laboratories run by research councils, or even by other government departments, are in danger of pricing themselves out of the market. This is because most contracts must bear a surcharge of $100 \%$ to meet overheads and administrative costs. It is difficult not to suggest that these could be greatly reduced by a simpler administrative structure.

There is even some criticism of university departments,
My main criticism of many university and polytechnic staff today is that they often assume that they cannot do worthwhile research unless they can land a substantial grant for that purpose. Even junior lecturers think they are justified in asking for a graduate research assistant. Yet even when they obtain this extra money, many are obviously less productive than the prewar lecturer who was lucky if he could obtain a few pounds from departmental funds for extra materials. It may well be that the present shortage of money will have its good results. Research workers may have to eschew problems requiring costly apparatus (much of which is accumulating dust up and down the country) and devote more time to thinking how to tackle problems within their own resources. They may even realise that some of the large grants which have been floating about in recent years have actually been counter-productive. We are said to be facing, in Britain, a financial crisis even more serious than that experienced in the 1930s. We should therefore remember that, in many subjects, it was then that Britain led the world in scientific research. the ground in a temporary facility until an ultimate waste disposal method has been found. Earlier this year, however, ERDA announced that it was reconsidering the whole problem and would issue a statement on the matter in due course.

With those disputes unresolved, and reactor sales at a virtual standstill, the immediate prospects for President Ford's goal of bringing 200 nuclear reactors on line by 1985 looks slim. But, in the absence of a strong, coherent energy policy featuring mandatory energy conservation and massive support for non-nuclear energy technologies, the nuclear power programme represents the only proven alternative to greatly increased oil imports. Faced with that prospect- Congress will be forced soon to take some controversial decisions. In the meantime, the nuclear energy industry will have to live with uncertainty. 